\title{
Dietary intake, adherence to Mediterranean diet and lifestyle-related factors in people with schizophrenia
}

Running title: Dietary intake in people with schizophrenia

Raquel Costa ${ }^{1}$, Scott Teasdale ${ }^{2,3}$, Sandra Abreu ${ }^{1}$, Tânia Bastos ${ }^{4,5}$, Michel Probst ${ }^{6}$, Simon Rosenbaum $^{3,7}$, Philip B.Ward ${ }^{3,8}$, Rui Manuel Corredeira ${ }^{1}$

${ }^{1}$ Research Centre in Physical Activity, Health and Leisure (CIAFEL), Faculty of Sport, University of Porto, Porto, Portugal.

${ }^{2}$ Keeping the Body in Mind Program, South Eastern Sydney Local Health District, Bondi Junction, Australia

${ }^{3}$ School of Psychiatry, UNSW Sydney, Sydney, Australia

${ }^{4}$ Centre of Research, Education, Innovation and Intervention in Sport (CIFI2D), Faculty of Sport, University of Porto, Porto, Portugal.

${ }^{5}$ Research Center in Sports Sciences, Health Sciences and Human Development, CIDESD, University Institute of Maia, ISMAI, Maia, Portugal.

${ }^{6}$ Faculty of Kinesiology and Rehabilitation Sciences, Research Group for Adapted Physical Activity and Psychomotor Rehabilitation, KU Leuven, Leuven, Belgium.

${ }^{7}$ School of Psychiatry, University of New South Wales, Sydney, Australia.

${ }^{8}$ Black Dog Institute, Randwick, Australia

${ }^{9}$ Schizophrenia Research Unit, South Western Sydney Local Health District \& Ingham Institute for Applied Medical Research, Liverpool, Australia

Corresponding author: Department of Adapted Physical Activity, Faculty of Sport, University of Porto. Rua Dr. Plácido Costa, n 91, 4200-450 Porto. Portugal. Tel.: +351 916200 685. E-mail address: raquelfcosta7@gmail.com (R. Costa) 


\section{Abstract}

Objectives: To examine the dietary intake of both inpatients and outpatients with schizophrenia in the Portuguese population as a potential key contributing factor to the poor physical health profiles, and understand the relationship of diet quality to other lifestyle factors. Methods: Participants of this cross-sectional study completed a semi quantitative food frequency questionnaire. Diet quality was determined by adherence to the Mediterranean Diet. In addition participants completed the International Physical Activity Questionnaire- Short Form and Pittsburgh Sleep Quality Index. Tobacco smoking was assessed through a series of general questions. Results: A total of 100 patients (50\% inpatients and $28 \%$ female) with schizophrenia were included in the final analysis. Patients reported a high consumption of caffeine, while deficits were evident for fibre and folate intakes, when compared to the European Food Safety Authority recommendations. Both inpatients and outpatients reported poor to moderate diet quality. Smokers reported poorer diet quality when compared to non-smokers ( $p<$ 0.001). Conclusions: Characteristics of dietary intake should be considered in further lifestyle interventions, in order to improve physical health of this population.

Keywords: Dietary patterns; diet quality; smoking; physical activity; sleep quality; schizophrenia 


\section{Introduction}

People with schizophrenia present two to three times higher rates of mortality when compared with general population (1-4). While a proportion of the excess of mortality is caused by suicide, the majority is related to natural causes (1). People with schizophrenia are at a more than fourfold increased risk for abdominal obesity (odds ratio $[\mathrm{OR}]$ of risk $=4.43)$, and more than double the risk of low HDL cholesterol $(\mathrm{OR}=$ 2.35), metabolic syndrome $(O R=2.35)$ and hypertriglyceridemia $(O R=2.73)$, and finally, almost twice the risk (by odds) for diabetes $(O R=1.99)$ and hypertension $(O R=1.36)$, when compared with general population (5). The association of these comorbidities and schizophrenia is a complex interplay between lifestyle-related factors, illness related factors (e.g., negative symptoms), and also effects of psychotropic medication treatment. Psychotropic medication treatment is associated with several metabolic side effects namely, weight gain, glucose intolerance, leptin and insulin resistance, dyslipidemia and alterations of cardiac function $(6,7)$.

Concerning lifestyle-related factors, people with schizophrenia have unhealthy lifestyle behaviours, including lack of physical activity (PA) (8-10), poor sleep quality $(11,12)$, high rates of tobacco smoking (13-15), alcohol consumption and substances abuse (16) and poor diet quality (16-19). In this population, dietary habits are generally characterized by a high intake total energy, saturated fat, sugar (20) and low intake of fibre, fruit and vegetables $(16,18,21,22)$.

Although there is a consensus regarding the influence of low socioeconomic status (23, 24), data on smoking behaviours and adherence to a healthy dietary pattern, remain inconsistent in people with schizophrenia (17). Moreover, differences between inpatients and outpatients have been unexplored. There is an increasing body of evidence concerning the influence of antipsychotic treatment in increase hunger and decrease satiety $(25,26)$. Specifically, second-generation antipsychotics are associated with an increase in appetite and food intake that can contribute to weight gain $(27,28)$. Additionally, adverse eating styles including disordered eating habits, fast-eating 
syndrome, and increased consumption of junk food and low food literacy have also been observed $(25,26,29)$. Concerning that, and due to the role of healthy diet on weight lost, insulin resistance, dyslipidemia and hypertension (30-32), traditional dietary patterns with proven benefits on health may be recommended for people with mental illness (33). A better understanding of the characteristics of dietary patterns in people with schizophrenia revealed great importance because diet are major and modifiable cause of cardiovascular disease (17). Furthermore, interventions targeting dietary patterns in people with schizophrenia could offer a greater benefit if synergetic effects can be detected in relation to metabolic syndrome-related conditions. Therefore, the current study has three major aims: i) assess the dietary intake of people with schizophrenia in a Portuguese population, comparing between treatment setting (inpatients and outpatients), ii) determine adherence to the Mediterranean diet, specifically analysing the difference between treatment setting (i.e., inpatients and outpatients), and iii) explore potential relationships between adherence to Mediterranean diet and lifestyle-related factors (PA, tobacco smoking and sleep quality).

\section{Materials and methods}

\subsection{Study design: participants and procedures}

The study was planned and implemented using the guidelines of the Strengthening the Reporting of Observational Studies in Nutritional Epidemiology (STROBE-nut) Statement (34). People diagnosed with schizophrenia from seven psychiatric centres, located in the northern region of Portugal, were invited to participate. Inclusion criteria were: (i) 18 years of age or older, and (ii) stabilised on psychotropic medication, defined as no medication changes within the last month. Exclusion criteria included: (i) an inability to provide informed consent, (ii) an inability to speak Portuguese, (iii) an inability to concentrate for at least 20 minutes (as determined by the treating psychiatrist), (iv) diagnosed with a neurological disorder, or (v) diagnosis of substance abuse or 
dependence in the previous six months. Psychiatric diagnosis of the participants was based on the Diagnostic and Statistical Manual of Mental Disorders (DSM-5) (35) criteria and was determined by treating psychiatrists. The study procedure was approved by the Faculty Ethics Committee (CEFADE 13.2014) and by each one of the seven psychiatric centres. All participants provided written informed consent.

\subsection{Instruments}

\subsubsection{Sociodemographic}

Socio-demographic details (e.g., age, educational level, current antipsychotic medication) and anthropometric measures (i.e., weight, height and waist circumference) were taken. Current antipsychotic medication was recorded for each participant and converted into a daily equivalent dosage of chlorpromazine (36). Weight was measured to the nearest $0.1 \mathrm{~kg}$ using a Tanita scale (BC-418MA, Tanita Corporation, Tokyo, Japan). Height was measured to the nearest $0.1 \mathrm{~cm}$ using a portable stadiometer (Siber Hegner). Waist circumference was taken horizontally at the halfway point between the patients' lowest rib and top of the iliac crest. Waist circumference was classified in ideal or in increased risks, according to Alberti et al. (37). In all procedures, participants wore light clothing with shoes removed. Body mass index (BMI) $\left(\mathrm{kg} / \mathrm{m}^{2}\right)$ was calculated and classified according to the World Health Organisation (38) categories of underweight, normal, overweight or obese (class I, II or III).

\subsubsection{Dietary intake assessment}

Dietary intake was recorded using a semi quantitative food frequency questionnaire (FFQ) of the previous 12 months, designed according to Willett (39) and adapted to include a variety of typical Portuguese food items (40). The FFQ comprises 86 food items or beverage categories, with a frequency section with nine possible responses (i.e., never to six or more times per day). Two previous studies have used the FFQ to assess the dietary intake in people with schizophrenia $(22,41)$. Food Processor Plus Software 
(ESHA Research, Salem, Oregon) was used based on values from the US Department of Agriculture. Values for typical Portuguese foods were computed using the Portuguese Tables of Food Composition (42). Nutrient intake data were obtained by multiplying the frequency of consumption of each food item by the nutrient content of the specified portion size, with once a day equal to one.

Adherence to the Mediterranean diet was determined according to the method developed by Trichopoulou et al. (43), and revised to include fish intake (44). Each of the nine components was assigned a value of 0 or 1 , using sex-specific median as the cut-off. For beneficial components (i.e., vegetables, legumes, fruits and nuts, cereal, and fish), value of 0 was assigned when consumption was below the median and value of 1 was assigned when consumption was at or above the median. For components presumed to be detrimental (i.e., meat, poultry, and dairy products), a value of 0 was assigned when consumption was at or above the median and a value of 1 was assigned when consumption was below the median. For alcohol, a value of 1 was assigned when consumption ranged between 5 and $25 \mathrm{~g}$ per day for women, and when consumption ranged between 10 and $50 \mathrm{~g}$ per day for men. For fat intake, the ratio of monounsaturated lipids to saturated lipids was used. Thus, the total Mediterranean diet score (MDS) ranged from 0 (minimal adherence to Mediterranean diet) to 9 (maximal adherence).

Estimated energy requirement (EER) was calculated for each subject using the Schofield equation (45) to determine basal metabolic rate (BMR) based on age, sex and weight, utilising adjusted body weight where appropriate (46). Each individuals BMR was then multiplied by a physical activity level to determine the EER (47). To assess for implausible data, the Goldberg et al. (1991) cut-off was utilised, with an estimated energy intake $(\mathrm{EEI}) / \mathrm{BMR}$ ratio of $<0.9$ considered to be underreporting (48). 
For males and females, the average daily intakes of energy, macro- and selected micro nutrients were compared to the follow references values: European Food Safety Authority (49), Babor et al. (50), and European Food Safety Authority (51).

\subsubsection{Lifestyle-related factors}

Moderate to vigorous PA [MVPA (min/week)] was determined using the Portuguese version of the Short-Form International Physical Activity Questionnaire (IPAQ-SF) (52). A cut-off $\geq 150$ minutes of MVPA per week discriminate between patients that follows the public health recommendation for adults (53).

Sleep quality was measured with the Portuguese version of Pittsburgh Sleep Quality Index (PSQI) (54). A global PSQI score higher than 5 indicates clinical levels of sleep disturbances (55), which represents poor sleep quality.

Tobacco smoking was assessed by two verbal questions from the investigator; (i) does the patient smoke, and (if the patient did smoke) (ii) how many cigarettes the patient smoked per day.

\subsection{Statistical analysis}

Demographic and clinical characteristics of the sample were expressed as either means and standard deviations or proportions, depending on the data type. Data were tested for normality using the Kolmogorov-Smirnov or Shapiro-Wilk test. Independent sample $t$ test was used to calculate the difference between energy intake and calculated energy requirement, and the average daily intakes between inpatients and outpatients. MannWhitney U-test was used to calculate the difference between caffeine consumption in smokers and non-smokers. For categorical variables, chi-square test was performed to identify differences between lifestyle-related factors. Statistical significance was set at $p$ $<0.05$. SPSS version 24.0 was used in all analyses (Chicago, IL, USA).

\section{Results}




\subsection{Sample characteristics}

A total of 115 Portuguese patients with a DSM-5 (35) diagnosis of schizophrenia were initially included in the analysis. A total of 15 (13.04\%) patients were considered to be reporting implausible data $($ El/BMR ratio of $<0.9)$, and consequently were excluded from the analysis. The final sample characteristics are presented in table 1. Results shows that $50 \%$ of the sample were inpatients, $46 \%$ had elementary level of education and $24 \%$ were employed. Regarding anthropometric characteristics, only $22 \%$ presented a normal weight, and $26 \%$ an ideal waist circumference. There were significant differences in age, employment and weight between inpatients and outpatients. Inpatients were older ( $p=$ $<0.001)$, more likely to be with employment $(p=0.02)$ and had a lower bodyweight $(p=$ 0.03), however BMI was not significantly different.

INSERT TABLE 1

\subsection{Average daily intakes}

Average daily intakes of energy, macro- and selected micro-essential nutrients and reference values for the total sample, inpatients and outpatients are presented in table 2. The total sample was in line with reference values for energy, macronutrients and macronutrient subgroups, and the majority of micronutrients. Fibre intake was significantly lower, and caffeine intake was significantly higher than the reference values. There were statistical trends to significance for inadequate pantothenic acid and folate intakes. Outpatients reported significantly higher intakes of energy, proteins, fat, and the majority of the vitamins, compared to inpatients.

INSERT TABLE 2

\subsection{Adherence to Mediterranean diet}


The consumption of each of the 9 components of the Mediterranean diet, for total sample, and the difference of food components between inpatients and outpatients are presented on table 3. Mean MDS score was 4.33, representing low to moderate adherence to the Mediterranean Diet. No significant difference was found in mean MDS scores between inpatients and outpatients. Although statistical differences were found in the meat and meat products subgroup $(109.69 \pm 41.90 ; 132.81 \pm 46.59$, respectively $)$ and fruits and nuts subgroup (186.62 $\pm 107.83 ; 256.62 \pm 128.30$, respectively).

\section{INSERT TABLE 3}

\subsection{Lifestyle-related factors}

Finally, regarding lifestyle-related factors, total score MDS was significantly higher in non-smokers $(5.20 \pm 1.18)$, compared with smokers $(3.86 \pm 1.67)(Z=-4.05 ; p<0.001$; $\left.\eta^{2}=0.152\right)$. Additionally, results showed that caffeine consumption in non-smokers (56.84 $\pm 47.65 \mathrm{mg} / \mathrm{day})$ is significantly lower compared with smokers (104.22 \pm 48.57 $\mathrm{mg} /$ day $)(Z=-3.62 p<0.001)$. No significant differences were found between good (4.41 $\pm 1.78)$ and poor sleepers $(4.26 \pm 1.54)\left(p=0.46 ; \eta^{2}=0.002\right)$. Due to the small number of patients $(8 \%)$ that follow the public health recommendations of MVPA per week (53) comparative analyses were not performed on PA behaviour.

\section{Discussion}

To the authors' knowledge, the present study is the first to analyse dietary patterns in Portuguese people with schizophrenia and to compare the difference in quality of diet between inpatients and outpatients with schizophrenia. Demographic characteristics of the participants showed higher rates of both elementary education level and unemployment. These factors could be barriers in achieving adequate dietary intakes, since socioeconomic status is associated with poor diet in people with schizophrenia (23, 
24). More specifically, in this population low socioeconomic status could be driving unhealthy and un-varied dietary intake, providing easy access to fast food and preprepared convenience foods (22). Anthropometric characteristics revealed that only a small number of participants presents a normal weight status as well as an ideal waist circumference, values that are consistent with the literature (56). Several factors can justify this situation, namely, adverse effect of antipsychotic medication (56-58), psychological factors (59-61) and unhealthy lifestyle (10, 12, 13, 17). Antipsychotic medication can increase hunger and decrease satiety $(25,26)$. Specifically the effects of second generation of antipsychotic medication on appetite and energy intake are likely key driving factors for elevated weight and waist circumference in people with schizophrenia (62). Furthermore, other medications (i.e., mood stabilizers and antidepressants) can also contribute to weight gain, and adversely affect lipid and glucose metabolism (63). Psychosocial factors have influence on the aetiology of obesity in people with schizophrenia by restricting food choices and decreasing caloric expenditure (59). Together with low education and high rates of unemployment, negative discrimination and social isolation could limit opportunities for access to healthier food and adopt adequate PA behaviours $(59,60,64)$.

In the present study, participants reported less energy intake that the calculated for energy requirement. In general population, under-reporting of dietary intake is a common problem in nutritional research and has been observed to persist across diet assessment methods (e.g., FFQ, $24 \mathrm{~h}$ recalls, food records) (65-68). Several determinants are associated with underreporting of energy intake, namely gender, older age, weight status and smoking. In addition, desired response behaviour or minimizing existing problems, as with alcohol consumption, for instance, cannot be excluded. In schizophrenia there is a lack of evidence regarding this problem. Given the cognitive, memory and motivational challenges in schizophrenia it is possible that under-reporting could be a significant issue. Identifying the determinants associated with under-reporting of dietary intake in 
people with schizophrenia may help to facilitate the adjustment of dietary assessment methods and the development of correction methods. Additionally, preliminary evidence $(28,69,70)$ has found that people with schizophrenia receiving antipsychotic medication have a reduced basal metabolic rate, suggesting that current formulas over estimate energy requirements. Further studies need to investigate this and develop modified formulas specific to this population if indicated.

In the total sample, mean fibre intake was significantly lower than recommended, while trends to statistical significance were present for inadequate folate and pantothenic acid intakes. These results are consistent with the greater literature $(17,22,71)$. Regarding the values for total fat, participants reported an adequate consumption. However, in the literature inconsistencies in the results were found. On the one hand some studies (16, $41,72,73)$ demonstrated that total fat intake was higher in patients compared with controls. One study (22) demonstrated that total fat intake was lower in patients compared with controls. In contrast, other studies $(18,21,23-25)$ reported non difference between patients and control groups for fat intake. In the present study, participants showed deficits in vitamin B9 (folate), which is consistent with a meta-analyses study in long-term schizophrenia (74). The lack of comparative studies for some nutrients, and the inconsistencies demonstrated for others nutrients reveals the need for more research in this field.

Finally, higher consumption of caffeine was reported in the present study. These results are well established in the literature, which reveals that both inpatients and outpatients with schizophrenia presented higher caffeine consumption compared with the general population $(75,76)$. Since caffeine consumption is associated with tobacco smoking $(77$, 78), findings of the present study are consistent with the literature, showing that caffeine consumption in non-smokers was significantly lower compared with smokers. According to Arrojo-Romero, Armas Barbazan (79), even after controlled for confounders, smoking was strongly and consistently associated with caffeine use and high caffeine use in both inpatients and outpatients with schizophrenia. In fact, tobacco smoking is associated with 
an induction of caffeine metabolism, and smokers tend to need two to three times more caffeine than non-smokers to reach the same plasma caffeine levels (80).

Despite the difference between inpatients and outpatients in some components of Mediterranean diet, the total score was similar, both presented a mean score of 4 that represents low to moderate adherence. Outpatients could have less structured time, increased opportunities to sleep, and miss meals resulting in lower dietary intake (22). On the other hand in inpatient conditions, the hospital environment naturally influenced the patients' nutrition and eating habits and therefore dietary intake could be more easily supervised.

It is conceivable that inpatients should consume a high quality diet, however while there are nutrition policies particularly targeting undernutrition in the general hospital, there is currently no specific nutrition standards targeted to the needs of mental health inpatients in Portugal. In addition, inpatients may have leave available allowing access to external food, which is often takeaway and other convenience options, and regular access to vending machines on the wards containing predominantly discretionary foods such as chips, soft drinks and sweets. Specific inpatient nutrition standards and vending machine policies appear necessary to improve the cardiometabolic health of mental health inpatients.

Concerning unhealthy lifestyles, in the present study, results showed that total minutes of MVPA per week were lower than public health recommendations of 150 minutes. This situation has already has been reported in previous study (8). Regarding sleep quality, more than a half of the sample were considered as poor sleepers, consistently with Cohrs (11) that indicated that 30 to $80 \%$ of people with schizophrenia present with sleep disturbances. Finally, consistently with the literature, high rates of tobacco smoking were reported (13-15).

Non-smokers reported a higher adherence to Mediterranean diet, compared with smokers. These results are consistent with previously published studies $(18,81)$. 
According to Bobes, Arango (81), smokers' patients were more likely to use salt, saturated fat and were less likely to follow a high-fibre and low-caloric diet. Is important to note that the relationship between MDS and PA was not possible to explore, due to the small sample size and the low MVPA levels of the participants. Regarding the importance of both health behaviours (i.e., diet and PA) for physical and mental conditions of people with schizophrenia, future studies should explore this interaction.

\subsection{Limitations and strengths of the study}

The strengths of this study include the comprehensive approach to evaluating and reporting dietary intake in people with schizophrenia, which is a clear limitation in previous studies (82). Assessing dietary patterns in people with schizophrenia presents a challenge given the common cognitive barriers. FFQ's represent a subjective and retrospective method, for that reason misreporting of portion size, food type and preparation methods occurs. According to Henderson, Borba (22), people with schizophrenia presents higher risk for misreporting. This highlights the need for a valid assessment method for assessing dietary intake in people with schizophrenia and other mental disorders (83). Despite this limitation, it is commonly used in people with schizophrenia $(22-24,41,73,84)$ as more accurate measures such as doubly-labelled water, nutritional biomarkers or weighed-food records are not considered feasible.

The FFQ does not account for nutritional supplements and therefore the nutrient intakes displayed in the tables may not be a true indication of overall intake but do demonstrate rates of dietary adequacy.

Given the cross-sectional study design, the results of this study should be interpreted carefully. The relationship between smoking and diet quality and caffeine consumptions requires further investigation. Longitudinal studies, assessing dietary intake at multiple time points, are required and may assist in gaining additional information about the 
contribution of dietary intake in symptomatology and in lifestyle behaviours in this population.

\subsection{Study implications for the Portuguese reality}

As dietary patterns could be a therapeutic target for metabolic abnormalities in patients with schizophrenia (17), a clear description of dietary intake will help determine intervention targets. Due to the limited literature concerning dietary practices and nutritional requirements in people with schizophrenia, the present findings could be important for clinical practice. The results found in this study revealed that people with schizophrenia need counselling concerning dietary intake, namely regarding caffeine consumption, energy intake, fibre and folate. At the same time intervention targets should also focus on better dietary pattern, for example increase the consumptions of fruit, vegetables and wholegrains, as well as in the reduction of processed and sweetened foods. Therefore, the results suggested that dietary and PA interventions targeting weight management, cardiometabolic health, diet quality, sedentary behaviour and cardiorespiratory fitness should be included in this population. To ensure the effectiveness of these interventions, the integration of dietitians and PA professionals (with experience in mental illness) into multidisciplinary mental health teams should be considered. Dedicated, expert clinicians delivering the interventions have the greatest impact on cardiometabolic health in mental illness (83).

\section{Conclusion}

People experiencing schizophrenia have low to moderate dietary quality in both inpatient and outpatient settings in Portugal likely contributing to the high rates of cardiometabolic complications. In addition, the high intake of caffeine and suboptimal intakes of fibre and folate present specific intervention targets. Incorporating nutrition interventions in both 
the inpatient and outpatient mental health services in Portugal may assist in improving poor physical health status of people with schizophrenia.

\section{Acknowledgements}

The authors would like to thank all of the participants, the collaborating psychiatrists', physiotherapists, nurses and physical activity teachers. We also would like to thank the

following participating centres: (1) Associação Nova Aurora de Reabilitação Psicossocial (ANARP), Porto, Portugal; (2) Psychiatric Department of Hospital São João, Porto, Portugal; (3) Casa de Saúde São José, Barcelos, Portugal; (4) Casa de Saúde São João de Deus, Barcelos, Portugal; (5) Casa de Saúde do Bom Jesus, Braga, Portugal; (6) Clinica do Outeiro, Vila do Conde, Portugal; (7) Associação dos Familiares, Utentes e Amigos do Hospital Magalhães Lemos, Matosinhos, Portugal. The Research Centre on Physical Activity Health and Leisure (CIAFEL) is supported by UID/DTP/00617/2013.

\section{Author Contributions}

$\mathrm{RC}$ was responsible for designing the study, writing the protocol, collecting and analyzing the data and producing the first draft of the manuscript.

ST and SA contributed to designing the study, interpreting results and helping writing the report.

TB, MP, SR, PBW and RMC provided feedback on the report and approved the final version.

\section{Declaration of interest}

The authors report no conflicts of interest.

\section{Funding}


No financial assistance was received in support of the study

\section{References}

1. Brown S, Inskip H, Barraclough B. Causes of the excess mortality of schizophrenia. The British journal of psychiatry : the journal of mental science. $2000 ; 177: 212-7$

2. Brown S, Kim M, Mitchell C, Inskip H. Twenty-five year mortality of a community cohort with schizophrenia. The British journal of psychiatry : the journal of mental science. 2010;196:116-21.

3. Saha S, Chant D, McGrath J. A systematic review of mortality in schizophrenia: is the differential mortality gap worsening over time? Arch Gen Psychiatry. 2007;64:1123-31

4. Correll CU, Solmi M, Veronese N, Bortolato B, Rosson S, Santonastaso P, et al. Prevalence, incidence and mortality from cardiovascular disease in patients with pooled and specific severe mental illness: a large-scale meta-analysis of $3,211,768$ patients and $113,383,368$ controls. World psychiatry : official journal of the World Psychiatric Association. 2017;16(2):163-80.

5. Vancampfort D, Wampers M, Mitchell AJ, Correll CU, De Herdt A, Probst M, et al. A meta-analysis of cardio-metabolic abnormalities in drug naive, first-episode and multi-episode patients with schizophrenia versus general population controls. World psychiatry : official journal of the World Psychiatric Association. 2013;12(3):240-50.

6. Osby U, Correia N, Brandt L, Ekbom A, Sparen P. Mortality and causes of death in schizophrenia in Stockholm county, Sweden. Schizophrenia research. 2000;45:21-8. 7. Stahl SM, Mignon L, Meyer JM. Which comes first: atypical antipsychotic treatment or cardiometabolic risk? Acta psychiatrica Scandinavica. 2009;119:171-9.

8. Faulkner G, Cohn T, Remington G. Validation of a physical activity assessment tool for individuals with schizophrenia. Schizophrenia research. 2006;82:225-31. 
9. Stubbs B, Firth J, Berry A, Schuch FB, Rosenbaum S, Gaughran F, et al. How much physical activity do people with schizophrenia engage in? A systematic review, comparative meta-analysis and meta-regression. Schizophrenia research. 2016;176(23):431-40.

10. Stubbs B, Williams J, Gaughran F, Craig T. How sedentary are people with psychosis? A systematic review and meta-analysis. Schizophrenia research. 2016;171(1-3):103-9.

11. Cohrs S. Sleep disturbances in patients with schizophrenia: impact and effect of antipsychotics. CNS Drugs. 2008;22:939-62.

12. Wulff K, Dijk DJ, Middleton B, Foster RG, Joyce EM. Sleep and circadian rhythm disruption in schizophrenia. The British Journal of Psychiatry. 2012;200:308-16.

13. Kalman D, Morissette SB, George TP. Co-morbidity of smoking in patients with psychiatric and substance use disorders. Am J Addiction. 2005;14(2):106-23.

14. Lasser K, Boyd JW, Woolhandler S, Himmelstein DU, McCormick D, Bor DH. Smoking and mental illness - A population-based prevalence study. Jama-J Am Med Assoc. 2000;284(20):2606-10.

15. McCreadie RG. Use of drugs, alcohol and tobacco by people with schizophrenia: case-control study. Brit J Psychiat. 2002;181:321-5.

16. Brown S, Birtwistle J, Roe L, Thompson C. The unhealthy lifestyle of people with schizophrenia. Psychological medicine. 1999;29(3):697-701.

17. Dipasquale S, Pariante CM, Dazzan P, Aguglia E, McGuire P, Mondelli V. The dietary pattern of patients with schizophrenia: a systematic review. J Psychiatr Res. 2013;47(2):197-207.

18. McCreadie RG. Diet, smoking and cardiovascular risk in people with schizophrenia - Descriptive study. Brit J Psychiat. 2003;183:534-9.

19. Stokes C, Peet M. Dietary sugar and polyunsaturated fatty acid consumption as predictors of severity of schizophrenia symptoms. Nutr Neurosci. 2004;7(4):247-9. 
20. Firth J, Stubbs B, Teasdale SB, Ward PB, Veronese N, Shivappa N, et al. Diet as a hot topic in psychiatry: a population-scale study of nutritional intake and inflammatory potential in severe mental illness. World psychiatry : official journal of the World Psychiatric Association. 2018;17(3):365-7.

21. Gupta A, Craig TK. Diet, smoking and cardiovascular risk in schizophrenia in high and low care supported housing. Epidemiol Psichiatr Soc. 2009;18(3):200-7.

22. Henderson DC, Borba CP, Daley TB, Boxill R, Nguyen DD, Culhane MA, et al. Dietary intake profile of patients with schizophrenia. Ann Clin Psychiatry. 2006;18:99105.

23. Roick C, Fritz-Wieacker A, Matschinger H, Heider D, Schindler J, Riedel-Heller S, et al. Health habits of patients with schizophrenia. Social psychiatry and psychiatric epidemiology. 2007;42(4):268-76.

24. Samele C, Patel M, Boydell J, Leese M, Wessely S, Murray R. Physical illness and lifestyle risk factors in people with their first presentation of psychosis. Social psychiatry and psychiatric epidemiology. 2007;42(2):117-24.

25. Blouin M, Tremblay A, Jalbert ME, Venables $\mathrm{H}$, Bouchard $\mathrm{RH}$, Roy MA, et al. Adiposity and eating behaviors in patients under second generation antipsychotics. Obesity (Silver Spring). 2008;16:1780-7.

26. Treuer T, Hoffmann VP, Chen AK, Irimia V, Ocampo M, Wang G, et al. Factors associated with weight gain during olanzapine treatment in patients with schizophrenia or bipolar disorder: results from a six-month prospective, multinational, observational study. World J Biol Psychiatry. 2009;10:729-40.

27. Fountaine RJ, Taylor AE, Mancuso JP, Greenway FL, Byerley LO, Smith SR, et al. Increased food intake and energy expenditure following administration of olanzapine to healthy men. Obesity (Silver Spring). 2010;18:1646-51.

28. Cuerda C, Velasco C, Merchan-Naranjo J, Garcia-Peris P, Arango C. The effects of second-generation antipsychotics on food intake, resting energy expenditure and physical activity. Eur J Clin Nutr. 2014;68:146-52. 
29. Hardy S, Gray R. The secret food diary of a person diagnosed with schizophrenia. J Psychiatr Ment Health Nurs. 2012;19(7):603-9.

30. Bonfioli E, Berti L, Goss C, Muraro F, Burti L. Health promotion lifestyle interventions for weight management in psychosis: a systematic review and metaanalysis of randomised controlled trials. BMC Psychiatry. 2012;12:78.

31. Bruins J, Jorg F, Bruggeman R, Slooff C, Corpeleijn E, Pijnenborg M. The effects of lifestyle interventions on (long-term) weight management, cardiometabolic risk and depressive symptoms in people with psychotic disorders: a meta-analysis. PloS one. 2014;9:e112276.

32. Wu MK, Wang CK, Bai YM, Huang CY, Lee SD. Outcomes of obese, clozapinetreated inpatients with schizophrenia placed on a six-month diet and physical activity program. Psychiatric services. 2007;58:544-50.

33. Teasdale SB, Samaras K, Wade T, Jarman R, Ward PB. A review of the nutritional challenges experienced by people living with severe mental illness: a role for dietitians in addressing physical health gaps. J Hum Nutr Diet. 2017.

34. Lachat C, Hawwash D, Ocke MC, Berg C, Forsum E, Hornell A, et al. Strengthening the Reporting of Observational Studies in Epidemiology-Nutritional Epidemiology (STROBE-nut): An Extension of the STROBE Statement. PLoS Med. 2016;13:e1002036.

35. American Psychiatric Association. Diagnostic and statistical manual of mental disorders DSM-5. 5th ed. London: American Psychiatric Publishing; 2013. 947 p.

36. Gardner DM, Murphy AL, O'Donnell H, Centorrino F, Baldessarini RJ. International consensus study of antipsychotic dosing. The American journal of psychiatry. 2010;167:686-93.

37. Alberti KG, Zimmet P, Shaw J. The metabolic syndrome--a new worldwide definition. Lancet. 2005;366:1059-62. 
38. World Health Organisation. Global Database on Body Mass Index: BMI $\begin{array}{llll}\text { Classification } 2016 & 2016 \text { [Available from: }\end{array}$ http://apps.who.int/bmi/index.jsp?introPage=intro 3.html.

39. Willett W. Food frequency methods. In: Willett W, editor. Nutritional Epidemiology. 2nd ed. New York: NY: Oxford University Press; 1998. p. 74-100.

40. Lopes C, Aro A, Azevedo A, Ramos E, Barros H. Intake and adipose tissue composition of fatty acids and risk of myocardial infarction in a male Portuguese community sample. J Am Diet Assoc. 2007;107:276-86.

41. Amani R. Is dietary pattern of schizophrenia patients different from healthy subjects? BMC Psychiatry. 2007;7(15).

42. Porto A, Oliveira L, editors. Tabela da composição de alimentos. Lisboa: Instituto Nacional de Saúde Dr. Ricardo Jorge, Centro de Segurança Alimentar e Nutrição; 2006. 43. Trichopoulou A, Kourisblazos A, Wahlqvist ML, Gnardellis C, Lagiou P, Polychronopoulos E, et al. Diet and Overall Survival in Elderly People. Brit Med J. 1995;311(7018):1457-60.

44. Trichopoulou A, Costacou T, Bamia C, Trichopoulos D. Adherence to a Mediterranean diet and survival in a Greek population. New Engl $J$ Med. 2003;348(26):2599-608.

45. Schofield WN. Predicting basal metabolic rate, new standards and review of previous work. Hum Nutr Clin Nutr. 1985;39 Suppl 1:5-41.

46. Krenitsky J. Adjusted body weight, pro: evidence to support the use of adjusted body weight in calculating calorie requirements. Nutr Clin Pract. 2005;20:468-73.

47. Black AE. Critical evaluation of energy intake using the Goldberg cut-off for energy intake : basal metabolic rate. A practical guide to its calculation, use and limitations. Int J Obesity. 2000;24(9):1119-30.

48. Goldberg GR, Black AE, Jebb SA, Cole TJ, Murgatroyd PR, Coward WA, et al. Critical-Evaluation of Energy-Intake Data Using Fundamental Principles of Energy 
Physiology .1. Derivation of Cutoff Limits to Identify under-Recording. Eur J Clin Nutr. 1991;45(12):569-81.

49. European Food Safety Authority. Overview on Dietary Reference Values for the EU population as derived by the EFSA Panel on Dietetic Products, Nutrition and Allergies (NDA): Summary of Dietary Reference Values - version 4; 2017.

50. Babor T, Higgins-Biddle J, Saunders J, Monteiro M. The Alcohol Use Disorders Identification Test: Guidelines for Use in Primary Care. second ed. Geneva: World Health Organization 2001.

51. EFSA Panel on Dietetic Products Nutrition and Allergies. Scientific Opinion on the safety of caffeine. EFSA Journal. 2015;13(5).

52. Craig CL, Marshall AL, Sjöström M, Bauman AE, Booth ML, Ainsworth BE, et al. International physical activity questionnaire: 12-country reliability and validity. Medicine \& Science in Sports \& Exercise. 2003;35(8):1381-95.

53. American College of Sports Medicine. ACSM's Guidelines for Exercise Testing and Prescription. Tenth ed. Philadelphia, PA: Wolters Kluwer; 2016.

54. Buysse DJ, Reynolds CF, 3rd, Monk TH, Berman SR, Kupfer DJ. The Pittsburgh Sleep Quality Index: a new instrument for psychiatric practice and research. Psychiatry research. 1989;28:193-213.

55. Waters F, Naik N, Rock D. Sleep, fatigue, and functional health in psychotic patients. Schizophrenia Research and Treatment. 2013;2013:425826.

56. De Hert M, Cohen D, Bobes J, Cetkovich-Bakmas M, Leucht S, Ndetei DM, et al. Physical illness in patients with severe mental disorders. II. Barriers to care, monitoring and treatment guidelines, plus recommendations at the system and individual level. World psychiatry : official journal of the World Psychiatric Association. 2011;10(2):13851.

57. De Hert M, Yu W, Detraux J, Sweers K, van Winkel R, Correll CU. Body weight and metabolic adverse effects of asenapine, iloperidone, lurasidone and paliperidone in 
the treatment of schizophrenia and bipolar disorder: a systematic review and exploratory meta-analysis. CNS Drugs. 2012;26:733-59.

58. Leucht S, Corves C, Arbter D, Engel RR, Li C, Davis JM. Second-generation versus first-generation antipsychotic drugs for schizophrenia: a meta-analysis. Lancet. 2009;373:31-41.

59. Daumit GL, Dickerson FB, Wang NY, Dalcin A, Jerome GJ, Anderson CA, et al. A behavioral weight-loss intervention in persons with serious mental illness. $\mathrm{N}$ Engl $\mathrm{J}$ Med. 2013;368(17):1594-602.

60. Thornicroft G, Brohan E, Rose D, Sartorius N, Leese M. Global pattern of experienced and anticipated discrimination against people with schizophrenia: a crosssectional survey. Lancet. 2009;373:408-15.

61. Manu P, Dima L, Shulman M, Vancampfort D, De Hert M, Correll CU. Weight gain and obesity in schizophrenia: epidemiology, pathobiology, and management. Acta psychiatrica Scandinavica. 2015;132(2):97-108.

62. Elman I, Borsook D, Lukas SE. Food intake and reward mechanisms in patients with schizophrenia: implications for metabolic disturbances and treatment with secondgeneration antipsychotic agents. Neuropsychopharmacology. 2006;31:2091-120.

63. Torniainen M, Mittendorfer-Rutz E, Tanskanen A, Bjorkenstam C, Suvisaari J, Alexanderson $\mathrm{K}$, et al. Antipsychotic treatment and mortality in schizophrenia. Schizophrenia bulletin. 2015;41:656-63.

64. Centorrino F, Wurtman JJ, Duca KA, Fellman VH, Fogarty KV, Berry JM, et al. Weight loss in overweight patients maintained on atypical antipsychotic agents. Int $\mathrm{J}$ Obes (Lond). 2006;30:1011-6.

65. Trijsburg L, Geelen A, Hollman PCH, Hulshof PJM, Feskens EJM, van't Veer P, et al. BMI was found to be a consistent determinant related to misreporting of energy, protein and potassium intake using self-report and duplicate portion methods. Public Health Nutr. 2017;20(4):598-607. 
66. Crispim SP, Geelen A, de Vries JH, Freisling H, Souverein OW, Hulshof PJ, et al. Bias in protein and potassium intake collected with 24-h recalls (EPIC-Soft) is rather comparable across European populations. Eur J Nutr. 2012;51(8):997-1010.

67. Freedman LS, Commins JM, Moler JE, Arab L, Baer DJ, Kipnis V, et al. Pooled results from 5 validation studies of dietary self-report instruments using recovery biomarkers for energy and protein intake. American journal of epidemiology. 2014;180:172-88.

68. Trabulsi J, Schoeller DA. Evaluation of dietary assessment instruments against doubly labeled water, a biomarker of habitual energy intake. Am J Physiol Endocrinol Metab. 2001;281(5):E891-9.

69. Nilsson BM, Forslund AH, Olsson RM, Hambraeus L, Wiesel FA. Differences in resting energy expenditure and body composition between patients with schizophrenia and healthy controls. Acta psychiatrica Scandinavica. 2006;114(1):27-35.

70. Cuerda C, Merchan-Naranjo J, Velasco C, Gutierrez A, Leiva M, de Castro MJ, et al. Influence of resting energy expenditure on weight gain in adolescents taking second-generation antipsychotics. Clin Nutr. 30. England2011. p. 616-23.

71. Fusar-Poli P, De Marco L, Cavallin F, Bertorello A, Nicolasi M, Politi P. Lifestyles and cardiovascular risk in individuals with functional psychoses. Perspect Psychiatr Care. 2009;45:87-99.

72. Ryan MC, Flanagan S, Kinsella U, Keeling F, Thakore JH. The effects of atypical antipsychotics on visceral fat distribution in first episode, drug-naive patients with schizophrenia. Life Sci. 2004;74:1999-2008.

73. Archie SM, Goldberg JO, Akhtar-Danesh N, Landeen J, McColl L, McNiven J. Psychotic disorders, eating habits, and physical activity: who is ready for lifestyle changes? Psychiatric services. 2007;58:233-9.

74. Wang D, Zhai JX, Liu DW. Serum folate levels in schizophrenia: A meta-analysis. Psychiatry research. 2016;235:83-9. 
75. Gurpegui M, Aguilar MC, Martinez-Ortega JM, Jurado D, Diaz FJ, Quintana HM, et al. Fewer but heavier caffeine consumers in schizophrenia: a case-control study. Schizophrenia research. 2006;86:276-83.

76. Strassnig M, Brar JS, Ganguli R. Increased caffeine and nicotine consumption in community-dwelling patients with schizophrenia. Schizophrenia research. 2006;86:26975.

77. Zimmermann A, Lubman DI, Cox M. Tobacco, Caffeine, Alcohol and Illicit Substance Use Among Consumers of a National Psychiatric Disability Support Service. Int J Ment Health Ad. 2012;10(5):722-36.

78. Gurpegui M, Jurado D, Luna JD, Fernandez-Molina C, Moreno-Abril O, Galvez R. Personality traits associated with caffeine intake and smoking. Prog Neuropsychopharmacol Biol Psychiatry. 2007;31:997-1005.

79. Arrojo-Romero M, Armas Barbazan C, Lopez-Morinigo JD, Ramos-Rios R, Gurpegui M, Martinez-Ortega JM, et al. Caffeine consumption in a long-term psychiatric hospital: Tobacco smoking may explain in large part the apparent association between schizophrenia and caffeine use. Schizophrenia research. 2015;164(1-3):234-41.

80. Gurpegui M, Aguilar MC, Martinez-Ortega JM, Diaz FJ, de Leon J. Caffeine intake in outpatients with schizophrenia. Schizophrenia bulletin. 2004;30(4):935-45.

81. Bobes J, Arango C, Garcia-Garcia M, Rejas J. Healthy lifestyle habits and 10year cardiovascular risk in schizophrenia spectrum disorders: an analysis of the impact of smoking tobacco in the CLAMORS schizophrenia cohort. Schizophrenia research. 2010;119:101-9.

82. Teasdale SB, Firth J, Stubbs B, Burrows TL. "You are what you eat" (not what you said you ate yesterday): Why a one-off 24-hour dietary recall fails capture usual dietary intake in schizophrenia. Schizophrenia research. 2018;199:447-8.

83. Teasdale SB, Ward PB, Rosenbaum S, Samaras K, Stubbs B. Solving a weighty problem: systematic review and meta-analysis of nutrition interventions in severe mental illness. The British journal of psychiatry : the journal of mental science. 2017;210:110-8. 
84. Chuang HT, Mansell C, Patten SB. Lifestyle characteristics of psychiatric outpatients. Canadian journal of psychiatry Revue canadienne de psychiatrie. 2008;53(4):260-6. 
Table 1. Demographic, anthropometric, clinical and lifestyle characteristics of people with schizophrenia $(n=100)$.

\begin{tabular}{|c|c|c|c|c|}
\hline Variables & $\begin{array}{c}\text { Total sample } \\
M \pm \text { SD }\end{array}$ & $\begin{array}{c}\text { Inpatients }(n=50) \\
M \pm S D\end{array}$ & $\begin{array}{l}\text { Outpatients }(n=50) \\
\qquad M \pm S D\end{array}$ & $p$ \\
\hline Age (years) & $44.57 \pm 9.68$ & $47.67 \pm 10.19$ & $41.48 \pm 8.14$ & $<0.001^{\dagger}$ \\
\hline \multicolumn{5}{|l|}{ Sex } \\
\hline Female (\%) & $28 \%$ & $28 \%$ & $28 \%$ & $1.00^{*}$ \\
\hline \multicolumn{5}{|l|}{ Employment situation } \\
\hline With employment (\%) & $24 \%$ & $34 \%$ & $14 \%$ & $0.02^{*}$ \\
\hline \multicolumn{5}{|l|}{ Educational level } \\
\hline Primary school (\%) & $17 \%$ & $26 \%$ & $8 \%$ & \\
\hline Elementary school (\%) & $46 \%$ & $50 \%$ & $42 \%$ & \\
\hline High school (\%) & $28 \%$ & $12 \%$ & $44 \%$ & \\
\hline University education (\%) & $9 \%$ & $12 \%$ & $6 \%$ & \\
\hline Weight (kg) & $80.92 \pm 17.12$ & $77.24 \pm 12.42$ & $84.62 \pm 20.26$ & $0.03^{* *}$ \\
\hline BMI $\left(\mathrm{kg} / \mathrm{m}^{2}\right)$ & $28.95 \pm 5.67$ & $28.29 \pm 9.93$ & $29.61 \pm 6.33$ & $0.25^{* *}$ \\
\hline \multicolumn{5}{|l|}{ Weight status } \\
\hline Underweight (\%) & $2 \%$ & $0 \%$ & $4 \%$ & \\
\hline Normal weight (\%) & $22 \%$ & $26 \%$ & $18 \%$ & \\
\hline Overweight (\%) & $32 \%$ & $38 \%$ & $26 \%$ & \\
\hline Obesity class I (\%) & $29 \%$ & $26 \%$ & $32 \%$ & \\
\hline Obesity class II (\%) & $12 \%$ & $6 \%$ & $18 \%$ & \\
\hline Obesity class III (\%) & $3 \%$ & $4 \%$ & $2 \%$ & \\
\hline Waist circumference (cm) & $99.62 \pm 16.70$ & $96.68 \pm 17.06$ & $102.56 \pm 15.98$ & $0.12^{\dagger}$ \\
\hline Ideal (\%) & $26 \%$ & $32 \%$ & $20 \%$ & $0.18^{*}$ \\
\hline \multicolumn{5}{|l|}{ Increased risks } \\
\hline Male >94 cm (\%) & $53 \%$ & $67 \%$ & $80 \%$ & $0.18^{*}$ \\
\hline Female $\geq 80 \mathrm{~cm}(\%)$ & $21 \%$ & $71 \%$ & $79 \%$ & $0.67^{*}$ \\
\hline $\begin{array}{l}\text { Chlorpromazine equivalent dose } \\
\text { (mg/day) }\end{array}$ & $573.38 \pm 537.58$ & $623.70 \pm 652.99$ & $523.08 \pm 390.24$ & $0.87^{\dagger}$ \\
\hline \multicolumn{5}{|l|}{ Antipsychotic medication } \\
\hline No antipsychotic (\%) & $5 \%$ & $8 \%$ & $2 \%$ & \\
\hline Monotherapy first-generation (\%) & $5 \%$ & $2 \%$ & $8 \%$ & \\
\hline Monotherapy second-generation (\%) & $31 \%$ & $24 \%$ & $38 \%$ & \\
\hline \multicolumn{5}{|l|}{ Combination of antipsychotics } \\
\hline First-generation (\%) & $11 \%$ & $14 \%$ & $8 \%$ & \\
\hline Second-generation (\%) & $17 \%$ & $6 \%$ & $28 \%$ & \\
\hline First- and second generation (\%) & $31 \%$ & $46 \%$ & $16 \%$ & \\
\hline MVPA (min/week) & $42.07 \pm 55.64$ & $42.60 \pm 56.60$ & $41.54 \pm 55.24$ & $0.60^{\dagger}$ \\
\hline$\geq 150$ minutes PA per week (\%) & $5 \%$ & $2 \%$ & $8 \%$ & $0.17^{*}$ \\
\hline Sleep quality global score & $7.9 \pm 4.1$ & $8.0 \pm 4.28$ & $7.92 \pm 4.00$ & $0.89^{\dagger}$ \\
\hline Poor sleepers (\%) & $57 \%$ & $56 \%$ & $58 \%$ & $0.84^{*}$ \\
\hline Smokers (\%) & $65 \%$ & $74 \%$ & $56 \%$ & $0.06^{*}$ \\
\hline Cigarettes per day & $10.4 \pm 10.8$ & $9.9 \pm 9.2$ & $11.00 \pm 12.30$ & $0.68^{\dagger}-$ \\
\hline
\end{tabular}

$\mathrm{SD}=$ standard deviation; $\mathrm{mg} /$ day $=$ milligram per day; $\mathrm{BMI}=$ body mass index; $\mathrm{MVPA}=$ moderate to vigorous physical activity; $\mathrm{PA}=$ physical activity. 
* Chi-square test

** Independent sample t-test 
Table 2. Average daily intakes of energy, macro- and selected micro nutrients for the study participants.

\begin{tabular}{|c|c|c|c|c|c|c|}
\hline & $\begin{array}{c}\text { Total sample } \\
M \pm S D\end{array}$ & Reference value & $p$ & $\begin{array}{c}\text { Inpatients } \\
M \pm S D\end{array}$ & $\begin{array}{c}\text { Outpatients } \\
M \pm S D\end{array}$ & $p$ \\
\hline Energy intake, kcal/day & $2130.3 \pm 433.2$ & 1791 to 2221 (i) ${ }^{c}$ & & $2020.1 \pm 361.9$ & $2240.5 \pm 472.6$ & 0.01 \\
\hline Protein, g/day & $98.9 \pm 23.5$ & 60 to $70(\mathrm{i})^{\mathrm{c}}$ & & $92.9 \pm 21.1$ & $104.9 \pm 24$ & 0.01 \\
\hline $\begin{array}{l}\text { Total carbohydrates, g/day } \\
\% \mathrm{EI}\end{array}$ & $\begin{array}{c}272.3 \pm 59.1 \\
49\end{array}$ & $45-60^{c}$ & & $\begin{array}{c}262.0 \pm 54.8 \\
50\end{array}$ & $\begin{array}{c}282.7 \pm 62.0 \\
48\end{array}$ & 0.08 \\
\hline Sugar, g/day & $111.6 \pm 38.4$ & & & $104.4 \pm 35.9$ & $118.8 \pm 39.7$ & 0.06 \\
\hline Complex Carbohydrate, g/day & $85.3 \pm 21.9$ & & & $80.7 \pm 18.4$ & $89.9 \pm 24.1$ & 0.35 \\
\hline Fibre, g/day & $21.6 \pm 6.6$ & $25^{c}$ & $<0.001$ & $20.3 \pm 5.9$ & $22.9 \pm 7.0$ & 0.05 \\
\hline Cholesterol, mg/day & $317.5 \pm 106.6$ & & & $291.3 \pm 100.2$ & $343.6 \pm 107.3$ & 0.02 \\
\hline Total fats, g/day $\quad \% E I$ & $\begin{array}{c}74.2 \pm 19.7 \\
31\end{array}$ & $20-35^{c}$ & & $\begin{array}{c}68.8 \pm 14.3 \\
30\end{array}$ & $\begin{array}{c}79.5 \pm 22.9 \\
31\end{array}$ & 0.006 \\
\hline Saturated fats, g/day $\%$ EI & $\begin{array}{c}22.6 \pm 7.0 \\
9\end{array}$ & $<10^{c}$ & & $\begin{array}{c}21.1 \pm 5.4 \\
9\end{array}$ & $\begin{array}{c}24.2 \pm 8.1 \\
10\end{array}$ & 0.03 \\
\hline Trans fat g/day $\quad \% E I$ & $\begin{array}{c}1.0 \pm 0.4 \\
<1\end{array}$ & $<1^{\mathrm{c}}$ & & $\begin{array}{c}1.0 \pm 0.4 \\
<1\end{array}$ & $\begin{array}{c}1.0 \pm 0.4 \\
<1\end{array}$ & \\
\hline Monounsaturated fats, g/day & $32.6 \pm 9.2$ & & & $30.5 \pm 6.4$ & $34.8 \pm 11.0$ & 0.02 \\
\hline Polyunsaturated fats, g/day & $12.5 \pm 3.6$ & & & $11.3 \pm 2.9$ & $13.7 \pm 3.8$ & 0.001 \\
\hline $\begin{array}{l}\text { Omega } 3 \\
\text { EPA + DHA } \\
\text { ALA }\end{array}$ & $\begin{array}{c}1.3 \pm 0.4 \\
0.396 \\
1.4\end{array}$ & $\begin{array}{c}0.250^{c} \\
0.5^{c}\end{array}$ & & $\begin{array}{c}1.2 \pm 0.4 \\
0.366 \\
1.5\end{array}$ & $\begin{array}{c}1.4 \pm 0.4 \\
0.425 \\
1.4\end{array}$ & $\begin{array}{l}\mathbf{0 . 0 5} \\
0.29 \\
0.20\end{array}$ \\
\hline Omega 6/Omega 3 ratio & $7 / 1$ & & & $7 / 1$ & $7 / 1$ & \\
\hline Caffeine, mg/day & $876.4 \pm 531.1$ & $400^{\mathrm{e}}$ & $<0.001$ & $886.7 \pm 487.2$ & $866.1 \pm 576.4$ & 0.85 \\
\hline Alcohol, g/day & $0.4 \pm 1.3$ & $<10$ to $<20$ (i) ${ }^{d}$ & & $0.3 \pm 1.0$ & $0.6 \pm 1.5$ & 0.21 \\
\hline Vitamin A, RE $\mu \mathrm{g} /$ day & $1791.6 \pm 919.7$ & 650 to $750(i)^{a}$ & & $1769.4 \pm 826.3$ & $1813.8 \pm 1012.5$ & 0.81 \\
\hline Vitamin B1 (Thiamine), mg/day & $1.7 \pm 0.4$ & $0.1^{\mathrm{a}}$ & & $1.7 \pm 0.3$ & $1.8 \pm 0.4$ & 0.04 \\
\hline Vitamin B2 (Riboflavin), mg/day & $2.1 \pm 0.6$ & $1.6^{\mathrm{a}}$ & & $2.0 \pm 0.5$ & $2.3 \pm 0.7$ & 0.04 \\
\hline Vitamin B3 (Niacin), mg/day & $23.7 \pm 5.7$ & $1.6^{\mathrm{a}}$ & & $22.3 \pm 4.9$ & $25.1 \pm 6.1$ & 0.01 \\
\hline
\end{tabular}




\begin{tabular}{|c|c|c|c|c|c|c|}
\hline Vitamin B5 (Pantothenic acid), mg/day & $4.8 \pm 1.2$ & $5^{b}$ & 0.06 & $4.6 \pm 0.9$ & $5.0 \pm 1.4$ & 0.09 \\
\hline Vitamin B6, mg/day & $2.2 \pm 0.6$ & 1.6 to $1.7(\mathrm{i})^{\mathrm{a}}$ & & $2.0 \pm 0.5$ & $2.4 \pm 0.7$ & $<0.001$ \\
\hline Vitamin B9 (Folate), $\mu \mathrm{g} / \mathrm{day}$ & $310.0 \pm 105.0$ & $330^{a}$ & 0.06 & $290.3 \pm 92.5$ & $329.6 \pm 113.8$ & 0.06 \\
\hline Vitamin B12, $\mu \mathrm{g} /$ day & $10.5 \pm 5.9$ & $4.0^{b}$ & & $19.5 \pm 5.3$ & $11.6 \pm 6.4$ & 0.08 \\
\hline Vitamin C, mg/day & $118.2 \pm 45.9$ & 95 to $110(\mathrm{i})^{\mathrm{a}}$ & & $103.7 \pm 34.0$ & $132.7 \pm 51.8$ & 0.001 \\
\hline Vitamin D, $\mu \mathrm{g} /$ day & $3.9 \pm 2.0$ & & & $4.3 \pm 2.0$ & $3.5 \pm 1.86$ & 0.03 \\
\hline Calcium, mg/day & $920 \pm 382$ & $950^{a}$ & 0.44 & $853.9 \pm 264.4$ & $986.3 \pm 464.4$ & 0.08 \\
\hline Iron, mg/day & $15.3 \pm 3.8$ & 11 to $16(\mathrm{i})^{\text {a }}$ & & $14.5 \pm 3.4$ & $16.0 \pm 4.1$ & 0.05 \\
\hline Magnesium, mg/day & $312.0 \pm 79.9$ & 300 to 350 (i) ${ }^{b}$ & & $285.5 \pm 65.5$ & $338.5 \pm 84.6$ & 0.001 \\
\hline Sodium, mg/day & $2071.9 \pm 630.6$ & $2000^{c}$ & & $1850.6 \pm 430.4$ & $2293.2 \pm 719.9$ & $<0.001$ \\
\hline Phosphorous, mg/day & $1398.1 \pm 377.8$ & $550^{b}$ & & $1287.3 \pm 293.9$ & $1508.8 \pm 420.7$ & 0.003 \\
\hline Potassium, mg/day & $3427.7 \pm 930$ & $3500^{b}$ & 0.44 & $3145.9 \pm 672.9$ & $3709.5 \pm 1064.3$ & 0.002 \\
\hline Zinc, mg/day & $12.1 \pm 3.2$ & $7.5-12.7^{c}$ & & $11.2 \pm 2.7$ & $13.1 \pm 3.4$ & 0.003 \\
\hline
\end{tabular}

(i) Range for women and men; $\mathrm{El}=$ energy intake; $\mathrm{RE}=$ retinol activity equivalents. ${ }^{\text {a }} \mathrm{RI}$ - reference intake;

b Al - adequate intake; c European Food Safety Authority (49); d Babor et al. (50); e European Food Safety Authority (51) 
2 Table 3. Components of the MDS, for total sample, and the difference between inpatients and 3 outpatients.

4

\begin{tabular}{|c|c|c|c|c|c|}
\hline $\begin{array}{l}\text { Components of the } \\
\text { MDS (g/day) }\end{array}$ & $\begin{array}{c}\text { Total sample } \\
\text { M } \pm \text { SD }\end{array}$ & $\begin{array}{c}\text { Inpatients } \\
M \pm S D\end{array}$ & $\begin{array}{l}\text { Outpatients } \\
M \pm S D\end{array}$ & $p$ & $\eta^{2}$ \\
\hline Fish & $66.12 \pm 36.70$ & $62.14 \pm 33.37$ & $70.10 \pm 39.69$ & 0.32 & 0.012 \\
\hline Meat and meat products & $121.25 \pm 45.59$ & $109.69 \pm 41.90$ & $132.81 \pm 46.59$ & 0.002 & 0.065 \\
\hline Dairy products & $382.22 \pm 267.13$ & $364.06 \pm 191.03$ & $400.38 \pm 327.12$ & 0.46 & 0.005 \\
\hline Legumes & $43.75 \pm 40.42$ & $46.83 \pm 34.37$ & $40.68 \pm 45.82$ & 0.06 & 0.006 \\
\hline Vegetables & $123.32 \pm 79.33$ & $113.72 \pm 70.98$ & $132.93 \pm 86.53$ & 0.28 & 0.015 \\
\hline Cereals & $296.91 \pm 79.80$ & $281.89 \pm 53.42$ & $311.94 \pm 97.73$ & 0.14 & 0.036 \\
\hline Fruits and nuts & $221.62 \pm 123.04$ & $186.62 \pm 107.83$ & $256.62 \pm 128.30$ & 0.001 & 0.082 \\
\hline Ethanol & $0.42 \pm 1.25$ & $0.27 \pm 0.96$ & $0.58 \pm 1.48$ & 0.17 & 0.016 \\
\hline $\begin{array}{l}\text { Ratio of monounsaturated } \\
\text { fatty acids to saturated } \\
\text { fatty acids }\end{array}$ & $1.48 \pm 0.28$ & $1.48 \pm 0.27$ & $1.48 \pm 0.30$ & 0.83 & 0.000 \\
\hline Total score MDS & $4.33 \pm 1.64$ & $4.18 \pm 1.45$ & $4.48 \pm 1.82$ & 0.21 & 0.008 \\
\hline \multicolumn{6}{|l|}{5} \\
\hline \multirow{2}{*}{\multicolumn{6}{|c|}{$\mathrm{M}=$ mean $\mathrm{SD}=$ standard deviation; MDS = Mediterranean Diet Score }} \\
\hline & & & & & \\
\hline \multicolumn{6}{|l|}{8} \\
\hline 9 & & & & & \\
\hline
\end{tabular}

